\title{
Mechanical Ventilation Complication
}

National Cancer Institute

\section{Source}

National Cancer Institute. Mechanical Ventilation Complication. NCI Thesaurus. Code C73505.

A disease or condition arising from the use of mechanical ventilation. 